\title{
Bio Ceramics: New Material from Mangrove Bark
}

\author{
Pratishtha Powar ${ }^{1, * *}$, Dattatray Gaikwad ${ }^{2}$ \\ ${ }^{1}$ Dada Patil Mahavidyalaya, Karjat, Dist. Ahmednagar 414402, Maharashtra, India \\ ${ }^{2}$ Subcenter-Osmanabad, Dr. Babasaheb Ambedkar Marathwada University, Aurangabad 431008, Maharashtra, India
}

*Corresponding author: E-mail: pratishthanagane13@gmail.com; Tel.: 7756853904

DOI: $10.5185 /$ amlett.2020.111573

Mangroves are salt-tolerant plants of tropical and subtropical intertidal regions of the world. The specific regions where these plants occur are termed as 'mangrove ecosystem'. They are having an ecological role as primary producers. In future there is a need to find out natural compounds to come over against chemical compounds. As these compounds reported to have carcinogenic effects. An attempt was made to find out largest sources of plants, the mangroves. They are facing various types of stresses; they are rich in several secondary metabolites. So, some mangrove barks are tested as a new source as a bio ceramic material by using bone marrow mesenchymal stem cells (BMMSCs). From the study it is revealed that among all tested barks, prop root bark of Rhizophora mucronata shows higher biocompatibility for cell adhesion. Thus, this study will enlighten the use of natural products to replaces chemical health hazards for ceramic material as ecofriendly materials.

\section{Introduction}

Mangrove forest constitutes a tidal wetland tropical forest ecosystem with a very special association of flora and fauna that live in the intertidal zones. Thus, it constitutes rich source for biodiversity and comprises variety of plant types like trees, shrubs, palms, epiphytes, ground ferns. grasses and other associated fauna [1]. Mangroves are found to arise in 121 countries casing 15 million ha worldwide; India comprises up to $3 \%$ of the global mangrove habitat [2]. The highest percentage of mangrove is reported between $5^{\circ} \mathrm{N}$ and $5^{\circ} \mathrm{S}$ latitudes. Near about $75 \%$ of world's mangroves are found in just 15 countries, out of which $42 \%$ largest area of the world's mangroves is in Asia, followed by Africa, North/Central America, Oceania and South America (21, 15, 12 and $11 \%$ respectively) [3]. Biocompatibility is also known as a tissue compatibility; it defines the capacity of a material to accomplish with proper host rejoinder when applied in future [4]. The inorganic Calcium Phosphate material is commonly preferred material used in medicine $[\mathbf{5 , 6}]$. This will be becoming largest sources of chemical compounds in future, which may cause hazardous effects over body of human being. So, there is an urgent need to find out natural compounds to come over against chemical compounds. Now a days, Biomaterial like Hydroxyapatite is a used in medical field as a substitute to chemical compounds, because of its nontoxic and anti-inflammatory activity $[\mathbf{7 , 8}]$. We are interested to enlightens and to find a bio ceramic material to the pharmacological world for the sustainable development. So, an attempt was made to study other biomaterials from plants like mangroves and to find out bio ceramic material as a new source of dental materials and substitute for bone recovering and enamel production.

\section{Materials and methods}

The plants were collected from Ratnagiri district, located in the west coast of Maharashtra state, India. The external stem bark of mangrove species Avicennia officinalis L. from family- Avicenniaceae, prop root and stem bark of Rhizophora mucronata Poir from family- Rhizophoraceae and stem bark of Sonneratia alba J. Smith from family- Sonneratiaceae were collected from Pawas estuaries of Ratnagiri Districts on 17 December 2013. The outer bark samples were cut into pieces, sundried and then oven dried at $60^{\circ} \mathrm{C}$. Dried bark samples were ground into powder and stored in an air tight plastic container.

\section{In vitro biocompatibility studies}

The biocompatibility in vitro of the bark samples was evaluated using microscopic methods given by Zhao et al. [9]. The Primary bone marrow mesenchymal stem cells (BMMSCs) were aspirated from the bone marrow of sheep (Ovis aries) and transferred in a test tube containing $50 \mathrm{ml}$ capacity. The cells were partially immersed in Dulbecco's modified Eagle medium supplemented with 10\% serum of same animal, $100 \mu \mathrm{g} / \mathrm{ml}$ Penicillin G, $100 \mu \mathrm{g} / \mathrm{ml}$, Streptomycin and $15 \mathrm{mg}$ bark samples supplemented on the surface of cultured bone marrow cells. The culture was maintained at $37^{\circ} \mathrm{C}$ in humidified atmosphere of $5 \% \mathrm{CO}_{2}$ for 7 days respectively. At the selected time points, surface layer of culture medium was removed for observation under 40X magnification microscope. (LEICA DM 2000 Microscope). Culture medium of the BMMSCs without spreading the bark powder considered as positive control. Surface adhesion of powder with BMMSCs was analyzed by using SEM. 


\section{Advanced Materials Letters www.vbripress.com/aml}

\section{Results and discussions}

SEM microphotographs of prop root and stem bark powder of $A$. officinalis, R. mucronata and $S$. alba is shown at 25000 magnifications in Fig. 1. It is observed from plate that $R$. mucronata prop root bark powder is highly porous while the A. officinalis, $R$. mucronata and $S$. alba stem bark powder shows large uneven crystals with deformities. The effect of powder of prop root and stem bark of A. officinalis, R. mucronata and S. alba on adhesion and cell proliferation of bone marrow mesenchymal stem cells (BMMSc) is shown in Fig. 2 and Fig. 3. Biocompatibility of the bark of $A$. officinalis, $R$. mucronata and $S$. alba was studied in vitro by observing the behavior of the BMMSCs after incubation. Plate 2 and 3 showed the micrographs of attachment of BMMS cells due to the bark powder, after incubation period of 3- and 7-days cell culture. It is observed from the micrographs that after 3 days culture, large number of cells stick on to the surface of bark powder. After 7 days, the populations of the BMMSCs increases significantly in response to $R$. mucronata prop root bark powder.

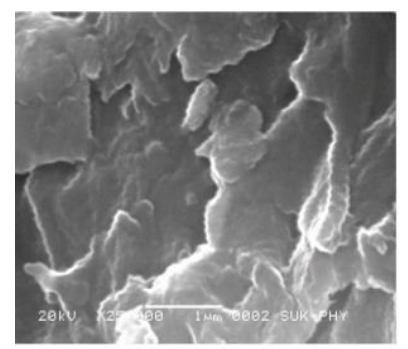

A. 0 .

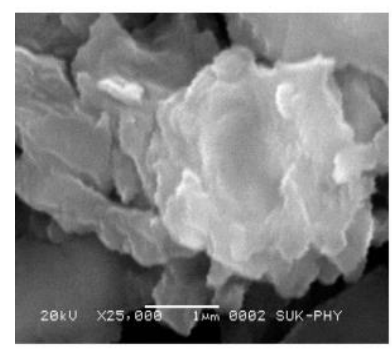

R. M. S.

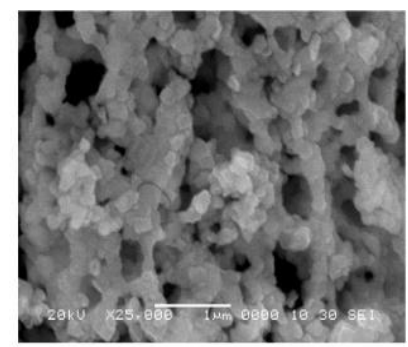

R. M. R.

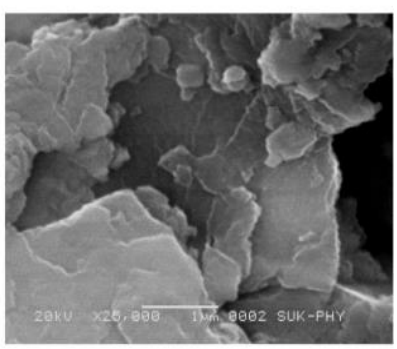

S. A.
Fig. 1. Scanning electron microscopy of mangrove bark powder at 25,000 magnification.

A. O. - Avicennia officinalis

R. M. R. - Rhizophora mucronata prop root

R. M. S. - Rhizophora mucronata stem

S. A. - Sonneratia alba

Biocompatibility is related to the behavior of biological materials in various fields. It is dealing with an appropriate host response to perform a particular function [10]. The process of tissue healing is a biological process which follows sequential changes of cellular and molecular events such as cell regeneration, proliferation, differentiation and production of various substances. Basic surgical manipulations are mainly for healing of damaged tissue, fractured bone or wound [11].

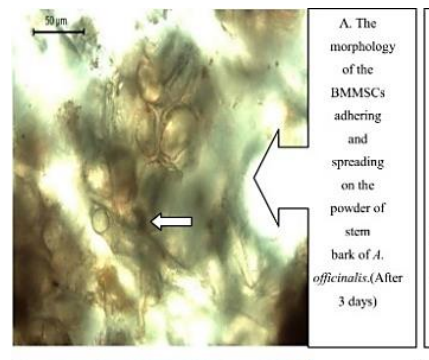

\section{www.iaamonline.com}

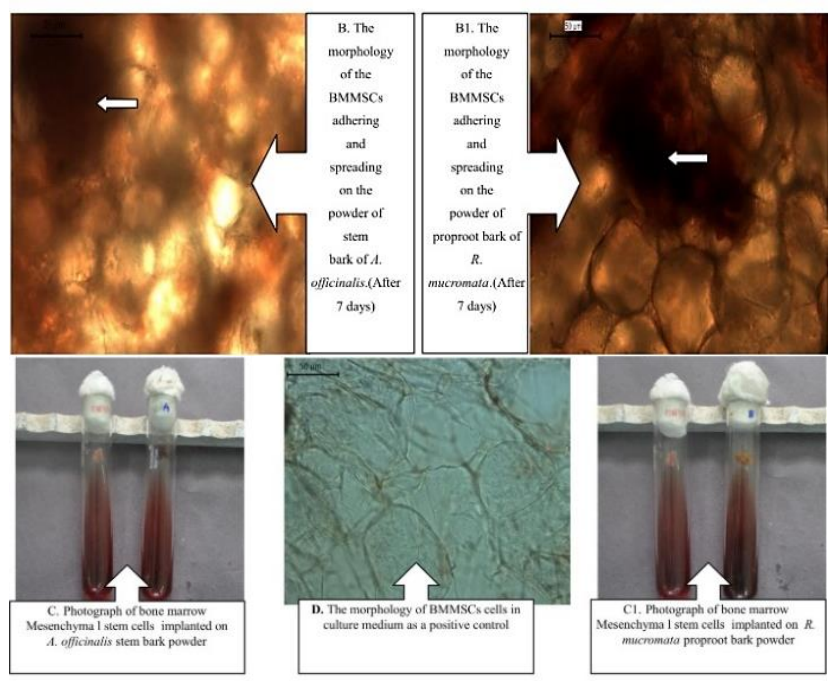

White arrows indicate the particles of plant leaf powder adhered to bone marrow cells

Fig. 2. Effect of bark powders on bone marrow mesenchymal stem cells-I.

Bone is an important part of the skeleton and metabolically active organ containing near about $10 \%$ of cardiac output constituting, deficiencies in vitamin $\mathrm{D}$ and calcium content which results in the osteopathy so, it is essential to maintain mineralization and calcium homeostasis for better structural integrity and health of skeleton [12]. The various phytomedicines and compounds derived from plant used in many herbal preparations which are affordable. Due to the side effects of synthetic drugs, problems of bone disorders have to be faced in many countries. Medicinal plants used against various bone disorders which are reported by several researches. The plants which as astringent, antiseptic, anti-inflammatory, antimicrobial and bio-stimulator have capacity to bone healing. The active constituents of $C$. quadrangularis encourage the proliferation and differentiation of Mesenchyama Stem Cells (MSC) which enhances the formation of new bone through the WntLRP5-B-Creatnin signaling pathway of pre-osteoblast formation [13]. There is an increasing interest to examine various preparations to find out biostimulators in tissue healing [11].

The clinical studies that Cissus quadrangularis accelerates the healing of femur osteomies in dogs [14]. $C$. quadrangularis distinctive character for higher rate of bone healing rate and results in early regeneration of all connective tissues by stimulating all cells of mesenchymal origin such as fibroblast, chondroblasts and osteoblasts [15]. 


\section{Advanced Materials Letters www.vbripress.com/aml}

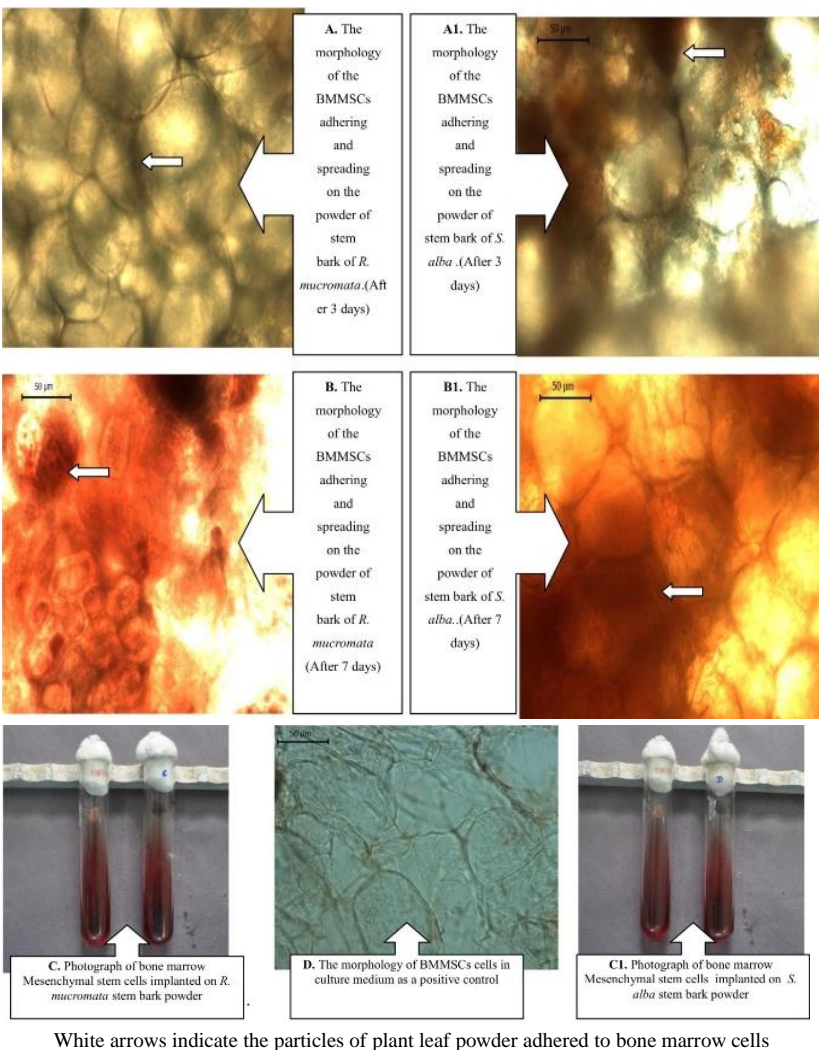

Fig. 3. Effect of bark powders on bone marrow mesenchymal stem cells-II.

The bioactive compounds determined from various plants such as stem of Allophyllus serratus, leaves of $C$. quadrangularis and leaves of Vitex negundo [16]. They found that isolated compounds of selected medicinal plants showed ostiogenic activities against various bone disorders. They noticed that some compounds that is routine from $A$. serratus, agnuside, negundoside and luteolin from $V$. negundo and 6'-o-trans cinnamoyl-cetapol from $C$. quadrangularis are responsible for varying influence exhibiting enhanced osteoblast mineralization. In-vitro studies of leaf powder of $A$. cobbe and A. serratus have a potent biocompatibility as cell growth adhesion and proliferations were considerably induced and displayed BMMSc adhesion and induction of good cell growth [17].

The BMMSCs morphologically attached on to the bark powder was evaluated using microscope. It is observed that R. mucronata prop root bark powder accelerates BMMSCs adhesion showing proportion of biocompatibility. Biocompatibility in human bone marrow cells cultured in minimum essential medium Eagle, alpha modification (aMEM) and Dulbecco's modified Eagle's medium (DMEM), for $35 \mathrm{D}$ and compared concerning morphologic appearance on scanning electron microscopy (SEM), cell viability and proliferation [18]. Bone marrow cells shows promotion of bone formation using highly pure porous $\beta$-TCP combined with bone marrow-derived osteoprogenitor cells [19]. Tricalcium silicate a synthetic medium for healing of bone which is analogous to calcium silicate indicates good biocompatibility found to be effective in tissue repair biomaterial when tested in bone marrow mesenchymal stem cells of goat [20].

Biocompatibility of Calcium hydroxyapatite (HAP) ceramics which is analogous to the mineral component of bones. This study investigated the in vitro biocompatibility study by the effect of calcium hydroxyapatite bio ceramics on cell adhesion of sheep bone marrow derived mesenchymal stem cells (BMMSCs), cultured in Dulbecco's modified Eagle medium for 3 and 7 days [21]. They found that a favorable biocompatibility, the calcium hydroxyapatite ceramics stimulated cell adhesion of the BMMSCs in vitro. Porous nature of Hydroxyapatite results into additional suitable situation for cell adhesion and Proliferation which results in to good biocompatibility character [22]. further, some initial biocompatibility tests are essential that allow various treatments to be evaluated without the necessity for ample and whole belief on in vitro animal testing and clinical trials [23].

In the present study also the $R$. mucronata prop root bark powder stimulates cell adhesion which is due to highly porous nature of $R$. mucronata bark powder (Plate 1 at 25000 magnifications). Thus, the $R$. mucronata prop root bark has a potent biocompatibility showing BMMSC adhesion and cell growth.

\section{Conclusion}

The highly porous nature of prop root bark powder of $R$. mucronata was showed while A. officinalis, $R$. mucronata and $S$. alba stem bark powder showed large uneven crystals with deformities. Biocompatibility of the bark of A. officinalis, $R$. mucronata and $S$. alba was studied in vitro by observing the behavior of the BMMSCs after incubation. The micrographs of cell attachment on to the bark powder after incubation period of 3-days and 7-days cell culture. After 3 days culture, large number of cells stick on to the surface of bark powder and after 7 days, the populations of the BMMSCs were increased significantly in response to $R$. mucronata prop root bark powder. The $R$. mucronata prop root bark powder stimulates cell adhesion due to highly porous nature of $R$. mucronata bark powder. Thus, the R. mucronata prop root bark has a significant biocompatibility showing BMMSC adhesion and cell growth. Thus, this study enriches the knowledge of natural bioproducts as ecofriendly materials and their use as substitute to carcinogenic chemicals.

\section{Acknowledgement}

The authors acknowledge the financial supports from the Research committee, IQAC, Head, Department of Botany and Principal, Dada Patil Mahavidyalaya, Karjat for giving grant for research and constant support to the research work.

\section{Conflicts of interest}

The authors declare that they have no competing interests.

\section{Keywards}

Avicennia, bark, bio ceramic, mangrove, rhizophora, sonneratia.

Received: 14 April 2020

Revised: 25 April 2020

Accepted: 01 September 2020 


\section{Advanced}

\section{References}

1. Chapman,V. J.; Wet coastal ecosystems. Elsevier, 1977, 428

2. Agoramoorthy, G.; Minna F.; Hsu, J.; Environmental Pollution, 2008, 155,2

3. Giri, C.; Ochieng, E.; Tieszen, L. L.; Zhu, Z.; Singh, A.; Loveland, T.; Masek J.; Duke, N.; Global Ecology and Biogeography, 2011, 20,1 .

4. Maul, T. M.; Massicotte, M. P.; Wearden, P. D.; Published, 2016.

5. Vallet-Ragi, M.; Gonzalez-Calbet, J. M.; Solid State Chem. 2004, 32,1 .

6. Dorozhkin, S. V.; Biology and Medicine Materials, 2009, 2.

7. Cai, Y. R.; Tang, R. K.; Mater Chem. 2008, 18, 3775.

8. Earl, J. S.; Wood, D. J.; Milne S. J.; J. Phys: Conference Series, 2006, 26, 268.

9. Zhao, W.; Wang, J.; Zhai, W.; Chang, J.; Biomaterials, 2005, 26

10. Adabi, M.; Naghibzadeh, M.; Adabi, M.; Ali, M.; Seyedeh, Z.; Esnaashari, S.; Seifalian, A. M.; Faridi-Majidi, R.; Aiyelabegan, H. T.; Ghanbari, H. Artificial Cells, Nanomedicine and Biotechnology, 2016.

11. Jung, M. K.; Callaci, J. J.; Lauing, K. L.; Otis, B. J.; Radek, K. A.; Jones, M. K.; Kovacs, E. J. Alcohol Clin Exp Res., 2011, 35, 3.

12. Ferretti, M.; Cavani, F.; Roli, L.; Checchi, M.; Magaro, M. S.; Bertacchini, J.; Palumbo, C.; Int, J Mol Sci. 2019, 20, 3.

13. Lordani, T. V.; de Lara, C. E.; Ferreira, F. B. P.; Monich,M. T.; da Silva, C. M.; Lordani, C. R.; Bueno, F. G.; Teixeira, J. J.; Lonardoni, M. V.; Mediators of Inflammation, 2018. Online.

14. Mait, S. K.; Saravanan, B.; Singh, G. R.; Naveen, K.; Hoque, M.; Lal, J. K.; Journal of Applied Animal Research, 2007, 31, 1.

15. Singh, V.; Singh, N.; Pal, U. S.; Dhasmana, S.; Mohammad, S.; Singh, N.; Natl. J. Maxillofac. Surg., 2011, 2, 2.

16. Kumar, M.; Rawat, P.; Mishra, D.; Gautam, A. K.; Pandey, R.; Singh, D.; Chattopadhyay, N.; Maurya, R.; Phytomedicine, 2010, 17 , 13.

17. Chavan, R. B.; Gaikwad D. K.; Indian Journal of Pharmaceutical Education and Research, 2017, 51, 3.

18. Coelho, M. J.; Cabral, A. T.; Fernandes, M. H.; Biomaterials, 2000 , 21.

19. Dong, J.; Uemura, T.; Shirasaki, Y.; Tateishi, T.; Biomaterials, 2002, 23, 23.

20. Qureshi, A.; Soujanya E.; Nandakumar; Pratapkumar; Sambashivarao; J. Clin. Diagn. Res., 2014, 8, 1.

21. Cassaro C. V.; Justulin, L. A.; de Lima, P. R.; Golim M.; Biscola, N. P.; de Castro, M. V. ; de Oliveira A. L.; Doiche, D. P.; Pereira, E. J.; _ Ferreira, R. S.; Barraviera B.; J. Venom Anim Toxins Incl Trop Dis., 2019, 25, e20190027.

22. Jagdale, P. N.; Jagtap, P. P.; Joshi, M. G. Bamane, S. R.; Advanced Materials Letters, 2016, 7, 4.

23. Perez-Mondragón, A.; Cuevas-Suarez, C.E.; Gonzalez-Lopez, J. A.; Trejo-Carbajal, N.; Melendez-Rodríguez, M.; Herrera-Gonzalez, A. M.; Dental Materials. 2020, 36, 4 . 